\title{
A EXPERIÊNCIA DE APRENDIZAGEM ON-LINE EM UM CURSO DE QUALIFICAÇÃO PROFISSIONAL EM SAÚDE
}

\author{
THE ON-LINE LEARNING EXPERIENCE IN A COURSE ON PROFESSIONAL QUALIFICATION \\ IN HEALTH
}

\author{
Josué Laguardia ${ }^{1}$ \\ Ângela Casanova ${ }^{2}$ \\ Rejane Machado ${ }^{3}$
}

Resumo Este artigo analisa as percepções a atitudes dos tutores e alunos nos processos de aprendizagem em um curso de atualização profissional on-line. Para tal realizaram-se entrevistas com dez alunos e três tutores desse curso mediante a utilização de roteiros semiestruturados que abrangiam os seguintes aspectos: ingresso no curso, tecnologias, conteúdos, atividades de avaliação, tutoria; mediação e expectativas quanto ao curso. Os roteiros foram organizados em tópicos que possibilitassem identificar as condições estruturais para o uso das ferramentas disponíveis no ambiente virtual, os tipos de interação, apreensão de conteúdos, bem como as expectativas dos participantes com relação aos objetivos propostos pelo curso. Os relatos dos entrevistados apontam questões importantes a serem consideradas na concepção e gestão de cursos on-line, tais como a necessidade de readequação periódica da proposta pedagógica do curso para atender as demandas dos alunos e tutores quanto à organização e atualização dos conteúdos, os meios de acesso ao material e a implementação de atividades avaliativas compatíveis com a experiência de trabalho.

Palavras-chave ambiente virtual de aprendizado; interação; educação a distância; aprendizagem on-line; qualificação profissional em saúde.
Abstract This article examines the perceptions regarding tutor and student attitudes in the learning processes during an on-line professional refresher course. In the study, interviews were carried out among ten students and three tutors of the course by means of semi-structured roadmaps that covered the following aspects: admission to the course, technologies, content, assessment activities, mentoring, mediation, and expectations about the course. The roadmaps were organized into topics that would enable the identification of the structural conditions for the use of the tools that were available in the virtual environment, the types of interaction, the understanding of the content, as well as participants' expectations with respect to the objectives proposed by the course. The interviewees' reports point to important questions to be considered when designing and managing on-line courses, such as the need for periodic adjustments of the course's educational proposal in order to meet the demands of both students and tutors with regard not only to how the content is organized but also to updating it, the means through which the material can be accessed, and the implementation of assessment activities that are consistent with work experience.

Keywords virtual learning environment; interaction; distance learning; on-line learning; professional qualification in health. 


\section{Introdução}

Os avanços nas tecnologias de informação e comunicação e a expansão da internet romperam as barreiras geográfico-temporais de acesso à educação profissional formal e não-formal. O surgimento da web no final dos anos 1990 possibilitou uma nova forma de aprendizagem baseada em computador, que se difundiu principalmente nos programas de pós-graduação, impulsionada pelo tipo de instrutor e a disponibilidade de sistemas integrados de aprendizagem (Moore e Kearsley, 2008).

A mediação das novas tecnologias na aprendizagem tem propiciado a formação de espaços educacionais apoiados em teorias socioconstrutivistas que resultaram em mudanças no processo de formação dos profissionais e, consequentemente, nas atitudes, percepções e usos dessas tecnologias nos processos de trabalho. Em acréscimo, a associação da educação continuada com as tecnologias de informação e comunicação e a flexibilidade da educação a distância resultaram na inclusão do local de trabalho como um espaço importante para a aprendizagem. A adoção da abordagem pedagógica oriunda dos espaços tradicionais de educação superior e da educação on-line, bem como as barreiras associadas às condições de trabalho e suas imbricações na vida pessoal demandam a investigação das melhores estratégias para a aprendizagem em determinados contextos organizacionais (Brosnan e Burgess, 2003; Osborne e Oberski, 2004). Desse modo, se há interesse em entender o impacto dessas novas tecnologias na pedagogia, é preciso levar em consideração as condições locais e a gama de respostas possíveis às pressões particulares. As formas assumidas pelas novas mídias são historicamente emergentes, em vez de tecnologicamente dadas, portanto elas são melhor compreendidas ao se examinar como as relações sociais estão inscritas na tecnologia e como esta é modelada para prover capacidades e funções específicas. Alguns achados de estudos apontam que as novas tecnologias de informação e comunicação (TIC) tendem a suplementar, em lugar de substituir, as práticas e formas de organização existentes e o impacto dessas tecnologias depende fortemente do contexto social em que estão inseridas. Os medos e riscos associados a elas estão distribuídos de forma desigual entre as classes sociais e os usuários adaptam as tecnologias a fim de estender seus repertórios sociais e intensificar a comunicação presencial (Clegg, Hudson e Steel, 2003).

A avaliação das atitudes e percepções dos usuários acerca da experiência de aprendizagem em ambientes virtuais, segundo Valcke e Leeuw (2004), possibilita compreender os fatores associados à apropriação e uso dos conhecimentos e habilidades desenvolvidos nesses contextos, bem como os elementos que promovem e limitam o uso dessas tecnologias. Na concepção socioconstrutivista, a interação social propiciada pelas ferramentas on-line modela o tipo de relações que emergem nesses contextos e é influenciada pela participação, 
engajamento e motivação dos atores em ambientes eletrônicos mais abertos e flexíveis. Os níveis de participação e interação humana são elementos críticos no sucesso das experiências de aprendizagem em ambientes virtuais pois possibilitam a criação de um alto nível de presença social que contribui significativamente para a efetividade das ações educacionais. A aprendizagem na teoria construtivista social baseia-se no desenvolvimento de significados compartilhados entre os participantes, tendo a interação, a colaboração e a reflexão crítica individual e coletiva como suportes fundamentais para o alcance de seus propósitos.

Os processos comunicativos e interativos, sejam em seus aspectos tecnológicos, cognitivos e afetivos que se realizam no interior de um ambiente virtual de aprendizagem (AVA), podem ter repercussões positivas ou não nas atitudes e sentimentos na aprendizagem do aluno. A interação, especialmente entre pares, está associada à satisfação com a aprendizagem e a qualidade geral do curso. A satisfação dos profissionais nas experiências de aprendizagem em ambientes virtuais é importante porque as reações positivas influenciam o apoio organizacional para a constituição de futuras formações e orientam acerca das mudanças nas estratégias formativas atuais (Wentling et al., 2000). Essa avaliação positiva depende também da interação entre o aprendiz e o ambiente virtual de aprendizagem, expressas pelas características de usabilidade das tecnologias de informação e comunicação.

Esses ambientes virtuais também oferecem os meios para avaliações das habilidades metacognitivas, das estratégias de aprendizagem e do histórico das mudanças ocorridas no desempenho dos participantes ao longo do curso. Estas avaliações proveem evidências acerca dos processos envolvidos nas atividades de construção do conhecimento em espaços digitais e dão subsídios aos formuladores e aos usuários sobre a efetividade das tecnologias de informação e comunicação nas iniciativas de aprendizagem colaborativa on-line (Gibson, 2003; Laguardia, Portela e Vasconcellos, 2007).

O emprego dos conhecimentos e habilidades adquiridos nos ambientes virtuais resulta tanto das experiências dos alunos nos processos de aprendizagem on-line quanto das condições contextuais de trabalho em que esses profissionais se encontram inseridos. As mudanças nos sistemas de saúde no aspecto assistencial, promovendo a saúde e a integralidade da atenção, e institucional, com a descentralização das ações e maior participação social, implicam alterações no âmbito pedagógico e na demanda educacional (Torrez, 2005). Para essa autora, a inclusão de novos atores da saúde requer a ampliação da escala de programas e estratégias educativas que levem em conta a busca por soluções criativas e colaborativas, apoiadas nas experiências profissionais e organizacionais, frutos de conhecimentos interdisciplinares e capazes de responder às necessidades do Sistema Único de Saúde. A educação a distância (EAD), ao prescindir da contiguidade espacial e temporal 
dos atores, possibilita a aprendizagem formal nos espaços de trabalho e estreita os laços entre a ação educacional e a ação laboral.

O objetivo deste artigo é descrever as atitudes, percepções e os usos das TIC pelos profissionais de saúde em cursos de pós-graduação lato sensu on-line. Esse conhecimento permite compreender quais são os requisitos necessários à aprendizagem em ambientes virtuais, de modo a fornecer subsídios aos formuladores de políticas de formação profissional para o aprimoramento das propostas educacionais a distância. O enfoque em cursos de pós-graduação deve-se ao fato de que a maior parte das iniciativas em EAD dirigida aos profissionais de saúde constitui-se em cursos dessa natureza.

\section{Metodologia}

Este artigo origina-se de uma pesquisa descritiva de abordagem qualitativa. Foram realizadas entrevistas semiestruturadas em uma amostra de dez alunos e três tutores de um curso de atualização on-line destinado a profissionais de saúde que atuam em serviços vinculados ao Sistema Único de Saúde, sendo em sua maioria oriundos das secretarias estadual e municipais do Rio de Janeiro.

Esse curso foi concebido sob o paradigma da construção socioindividual do conhecimento, em processos interativos mediados pelas tecnologias de informação e comunicação, síncronas e assíncronas, em espaços de colaboração entre tutores e alunos. O curso foi realizado totalmente on-line em uma plataforma de aprendizagem virtual (Vias-K). O conteúdo, disponível nesse ambiente virtual, estava agregado em três eixos temáticos, sendo cada eixo composto por unidades de aprendizagem e módulos. Além do conteúdo, essas unidades possuíam exercícios de pergunta e resposta, atividades interativas (fórum de discussão) e exercícios práticos. As estratégias de avaliação implementadas nessas unidades foram exercícios autocorrigidos, trabalhos escritos (questão discursiva), participação nos fóruns de discussão e testes (questões objetivas). As avaliações do tutor acerca da resposta do aluno às questões discursivas e a participação nos fóruns, assim como as notas obtidas nas avaliações das questões objetivas, puderam ser monitoradas pelo aluno através da ferramenta de acompanhamento. Coube ao tutor realizar o cadastramento e a abertura de cada fórum no ambiente de ensino. A carga horária total do curso foi de 100 horas, correspondendo a uma duração média de aproximadamente quatro meses, tendo sido sugerido aos alunos que estudassem de uma a duas horas por dia.

Nas entrevistas realizadas com a amostra de alunos e tutores do curso foram utilizados roteiros que procuraram abranger os seguintes aspectos: ingresso no curso, tecnologias, conteúdos, atividades de avaliação, tutoria; 
mediação e expectativas quanto ao curso. Os roteiros foram organizados em tópicos que possibilitassem identificar as condições estruturais para o uso das ferramentas disponíveis no ambiente virtual, os tipos de interação, tais como a interação aluno-conteúdo, aluno-tutor, aluno-aluno e aluno-interface e aquelas que propiciam e limitam a aplicação dos conhecimentos na prática profissional. Buscou-se também descrever como são apreendidos os conteúdos, as expectativas dos alunos/participantes frente aos objetivos propostos e identificar as percepções e valores atribuídos ao curso na transformação do processo de trabalho dos alunos/participantes. Além de permitir obter informações sobre as questões propostas pelo entrevistador, a técnica de entrevista semiestruturada também ofereceu ao entrevistado a possibilidade de inclusão de outras questões que fossem de interesse da pesquisa.

As entrevistas foram gravadas, transcritas e analisadas com base nas estratégias de codificação da 'teoria ancorada nos dados' e análise de conteúdo. Para tal, procedeu-se à codificação aberta, na qual foram extraídas as expressões e termos referidos pelos entrevistados. A partir dessa lista de expressões foram identificadas categorias, ordenadas nas subcategorias - expectativas; acesso; percepções acerca do conteúdo, do tutor e do ambiente; adequação dos conteúdos à prática; abordagem de estudo; estratégias pedagógicas dos tutores; habilidades cognitivas e metacognitivas; aplicação no trabalho. Na etapa subsequente, realizou-se a codificação seletiva dessas subcategorias, reagrupadas nas categorias - acessibilidade, interação e aplicabilidade, que compõem a categoria-chave 'aprendizagem profissional on-line. Essa categoria-chave organizaria a experiência da aprendizagem dos alunos de um curso on-line em um hipotético modelo teórico. Todavia, optou-se por separar os achados a partir da perspectiva dos atores, a fim de dar uma visão mais integrada da inter-relação dessas categorias no processo de aprendizagem profissional on-line.

\section{Resultados}

Dentre os dez alunos entrevistados, nove eram do sexo feminino, tinham idade média de 42 anos, oito possuíam formação na área da saúde e todos tinham vínculo com as secretarias estadual e municipais de Saúde do Rio de Janeiro. Os três tutores entrevistados eram do sexo feminino, média de idade de 37 anos, com formação na área de saúde, mestrado e/ou doutorado em Saúde Pública, experiência de docência presencial e vinculação com o serviço público federal ou estadual.

A seleção dos tutores foi feita de maneira informal, através de convite da coordenação do curso, baseado no potencial e nas habilidades para a tutoria ou interesse em vivenciar a experiência de educação on-line. Essas habilidades, 
de acordo com o relato dos tutores, repousaram na sua capacidade para 'alfabetizar' o aluno no uso da internet e do ambiente virtual, bem como articular os conteúdos do curso, o que requeria uma formação em saúde pública. Dois tutores relataram terem participado de uma capacitação para tutoria fornecida pela coordenação de educação a distância da instituição que oferecia o curso.

\section{O curso sob a ótica dos tutores}

Os tutores mencionaram que a experiência da tutoria on-line serviu para dirimir dúvidas e desconstruir preconceitos a respeito da educação a distância. $\mathrm{Na}$ opinião deles, essa modalidade de ensino (EAD) tem como aspectos positivos a possibilidade de ampliar o acesso a um número maior de alunos e de instituir outra dinâmica de construção do conhecimento, que parte da prática para a teoria e que se apoia na interação via ferramentas de comunicação. Desse modo, sob o seu ponto de vista, a EAD requer uma 'boa' abordagem pedagógica e a responsabilidade do aluno no gerenciamento do seu estudo.

$\mathrm{O}$ acesso dos tutores ao AVA foi feito, na maioria das vezes, no domicílio, nos dias de semana à noite e nos finais de semana. Essa escolha decorreu da preferência por um espaço e horário considerado mais tranquilo para leitura e avaliação das atividades dos alunos, sem ser interrompido pelas demandas do serviço no local de trabalho.

A impressão acerca do ambiente do curso foi de que se tratava de um espaço contendo aspectos interessantes, mas com limitações em face da presença de problemas operacionais, que desestimulariam os alunos, como, por exemplo, a falta de uma ferramenta de busca para acessar uma página específica do conteúdo do curso e também a forte dependência da comunicação por meio da escrita. A despeito dessas limitações, os tutores consideraram que poucos alunos tiveram dificuldades no uso do AVA, dada a baixa frequência desses relatos.

Quanto às ausências de material impresso ou da opção para descarregamento (download) do conteúdo do curso, os tutores entrevistados apontaram como um 'fator negativo' o desconforto da leitura na tela do computador e a transferência dos conteúdos do AVA para um editor de textos ('corta-e-cola'). Como 'fatores positivos', destacam a necessidade de o aluno acessar o ambiente virtual e a economia dos custos de impressão. Entretanto, a possibilidade da leitura de material impresso em situações em que os alunos não se encontram on-line, mas com disponibilidade de tempo para estudo, sugere que os conteúdos do curso sejam oferecidos em arquivos digitais para impressão. A necessidade de estudo na tela do computador foi questionada, inclusive do ponto de vista das implicações ergonômicas para a saúde dos tutores e 
alunos, seja pelo esforço físico exigido na leitura, seja pelo volume de material textual, aspecto que assinalaria também a predominância de uma estratégia pedagógica em detrimento de outras, uma vez que a aprendizagem não se resume à leitura.

acho muito cruel o aluno ficar na frente do computador fazendo o curso on-line; ele poderia ter a possibilidade de fazer em outro espaço físico, com outra postura [...] (Tutor 1).

Além disso, a novidade de alguns temas do curso exigiu maior tempo de dedicação ao mesmo e, consequentemente, maior tempo de estudo.

Porque para a maioria deles era coisas muito novas. Eles falavam isso... que nunca tinham visto isso na vida. 'Geoprocessamento', [...] muita gente não conhecia isso. Então eles tinham que estudar mesmo. Não era só ler e pronto (Tutor 3).

Foi apontado que a atualização periódica dos conteúdos e a revisão da abordagem pedagógica, ambas apoiadas na experiência de alunos e tutores, poderia ajustar o caráter fortemente teórico das atividades aos desafios do trabalho, adequar o volume das atividades ao cronograma, bem como estreitar a articulação entre os conteúdos das unidades.

uma avaliação que eu faço em relação às atividades pedagógicas do curso é que [...] elas deveriam estar mais voltadas para o desafio do trabalho, do serviço, [...] ainda são atividades pedagógicas muito teóricas [...] não tem como desafio o trabalho de quem está fazendo, não consideram a experiência prática do aluno (Tutor 1).

Não obstante, a vivência da tutoria mostrou que a atualização dos conteúdos em um curso on-line não se apresentava de modo tão simples e rápido quanto parecera inicialmente. Enquanto nos cursos presenciais o professor tem autonomia para modificar suas apresentações audiovisuais (p. ex, PowerPoint), neste curso on-line, os conteúdos foram elaborados inicialmente por 'professores-conteudistas', revistos por designers instrucionais e, em seguida, inseridos no ambiente virtual de aprendizagem por programadores. Isso implicou em uma menor agilidade para adequar os aspectos teóricos e práticos dos cursos em face das demandas e necessidades dos alunos e à dinâmica dos processos de trabalho.

A elaboração do material didático por 'professores-conteudistas', que não eram necessariamente tutores do curso, gerou em alguns casos dificuldades para que estes conseguissem responder às dúvidas dos alunos. Uma das estratégias adotadas para contornar essa situação foi a realização de um encontro entre esses 'professores-conteudistas' e os tutores do curso com 
vistas a uma melhor compreensão do tema, das estratégias pedagógicas subjacentes às atividades e da articulação entre os conteúdos do curso. Os trabalhos escritos realizados ao longo do curso foram identificados como uma das estratégias que propiciaria a melhor articulação dos conteúdos. Por sua vez, essa articulação seria também uma das principais habilidades para o trabalho de tutoria, exigindo desse profissional tanto um conhecimento do tema, favorecido pela formação em saúde pública, quanto uma experiência prática em gestão e planejamento. Essa articulação foi vista ainda como elemento facilitador da ação do tutor frente à experiência educacional dos alunos, em geral com conhecimentos 'estanques' e 'fragmentados'.

Então, na medida em que o conteúdo propicia isso, fica mais rica a intervenção do tutor. Agora, por outro lado, também só o conteúdo ser articulado, sem que o tutor estimule essa visão de articulação, eu acho que nem sempre o aluno faz. Porque os nossos alunos são montados no modelo cartesiano, muito fragmentado, muito estanque, onde acham que acabou uma disciplina, acabou, [...] agora vou começar outra coisa (Tutor 2).

Os tutores entrevistados destacaram outras habilidades para a atividade de tutoria: a capacidade de 'alfabetizar' o aluno no uso da internet e do ambiente virtual de aprendizagem, o domínio da linguagem escrita e de síntese para comunicação e interação com os alunos, a fim de permitir a expressão em poucos parágrafos de ideias que, na situação presencial, poderiam consumir horas de aula. A generosidade em compartilhar ideias, a tranquilidade para lidar com as limitações da comunicação escrita, a sensibilidade para encontrar momento e local mais adequados para incentivar os alunos, a criatividade para elaborar questões capazes de despertar seu interesse e o 'jogo de cintura' constituiriam aspectos afetivos importantes destacados para a atuação do tutor. Um tutor expressa sua preocupação em controlar a ansiedade para não sobrecarregar os alunos com muitas informações e a angústia gerada pela interação a distância:

Para ser tutora $[\ldots]$ tem que ter paciência, [...] saber estimular o aluno. Porque assim, bem ou mal, o curso a distância é uma coisa nova. As pessoas não estão muito acostumadas. É uma cultura que tem que ser adquirida. Então se a pessoa não for muito disciplinada, acaba deixando para lá (Tutor 3).

A ocorrência de reuniões periódicas entre tutores e a coordenação do curso estabeleceu um espaço para discussão de critérios para avaliação e comunicação com os alunos, discussão de problemas técnico-operacionais com o AVA e mediação entre o aluno e a coordenação do curso. Essas reuniões serviram também para a reflexão teórico-prática e a criação coletiva de um 
roteiro de orientação para os tutores, contendo dicas de assuntos a serem tratados nos fóruns e referências bibliográficas para inclusão na biblioteca do curso. Ademais, a participação nessas reuniões contemplou aspectos da tutoria que, segundo os entrevistados, não foram tratados no curso de formação de tutores oferecido na ocasião, considerado pelos entrevistados como conceitual, genérico e limitado às questões de funcionamento do AVA.

Os tutores relataram o uso de algumas estratégias para o exercício da tutoria, tais como: do sujeito indefinido para correção de conceitos cuja compreensão foi equivocada; da redação prévia das respostas; da ferramenta 'mural' para instigar/incentivar a participação dos alunos; das mensagens postadas no fórum para extrair temas/assuntos a serem abordados nas mensagens aos alunos e a leitura dos textos das unidades antes do início dos fóruns, para aumentar a familiaridade com o tema em discussão. Outra estratégia mencionada foi estimular os alunos a buscarem outras referências e informações frente às suas dúvidas, a fim de estimularem o processo de investigação e reflexão. Essa estratégia questiona tanto a ideia de que a eficiência do tutor estaria relacionada ao imediatismo da resposta quanto a cultura do 'videoclipe', isto é, a perspectiva de que a informação deve ser o mais processada possível para favorecer a aprendizagem. A própria dinâmica da modalidade de ensino a distância onde tutores e alunos têm horários de acesso específicos e muitas vezes distintos durante o dia levaria a variações no tempo de resposta de tutores e, por conseguinte, na expectativa dos alunos por uma resposta imediata.

O fórum foi considerado o principal espaço de acompanhamento do aluno e de articulação de conteúdos do curso, referida por um tutor como uma 'ágora', ou seja, um espaço coletivo que implicaria mais em respostas do tutor ao grupo do que a um participante específico. Essa percepção explicaria o uso pelo tutor do sujeito indefinido e a resistência em nomear os alunos nas mensagens postadas nos fóruns, fazendo-o apenas para destacar aspectos positivos.

Eu acho que o mais rico do curso é o fórum; o fórum em termos de qualidade de ensino-aprendizagem, de aprendizagem coletiva; é o fórum que possibilita isso como ferramenta (Tutor 1).

Ao contrário do fórum, a sala de bate-papo (chat) do AVA não foi percebida como uma boa estratégia pedagógica. O caráter síncrono da ferramenta exige a presença de todos em um mesmo horário no AVA e, por esta razão, não poderia, segundo os tutores, ser utilizado para avaliação dos alunos, 4 já que nem sempre um aluno teria a disponibilidade para participar. Além disso, os problemas técnicos no uso do chat foram citados como elemento desestimulador à participação dos alunos, o que levou à suspensão do seu uso 
no processo de aprendizagem, naquela ocasião. 5 A melhoria na comunicação com o suporte da coordenação de educação a distância da instituição provedora do curso referente aos aspectos operacionais do ambiente foi descrita pelos tutores como fundamental para evitar o ressurgimento de problemas corrigidos em experiências com edições anteriores do curso e o ônus institucional decorrente da má impressão que esses problemas causariam nos alunos.

No que se refere às estratégias avaliativas, a disponibilidade de um conjunto de questões objetivas a serem respondidas ao final de cada unidade de aprendizagem, com acesso subsequente ao gabarito das respostas, foi valorado positivamente como mais um dispositivo que propicia um processo reflexivo ao aluno. Ao contrário, as questões objetivas inseridas no interior das unidades de aprendizagem com vistas a um processo de autoavaliação foram consideradas, por um dos tutores, como pouco eficientes para a reflexão do aluno, além de dificultar a 'navegação' no AVA para os módulos subsequentes. De modo geral, as atividades de avaliação foram consideradas muito teóricas, apoiadas na repetição ou articulação com os temas estudados, sem considerar a aplicação desses conteúdos no processo de trabalho do aluno. Para a correção das atividades discursivas, uma das estratégias adotadas foi a leitura prévia de todos os trabalhos para só então emitir a nota/ conceito, considerando-se assim o desempenho da turma como um todo.

Uma questão importante e atual na EAD, apontada também pelos entrevistados deste estudo, foi a ocorrência de plágio e os desafios para se lidar com esse problema. $6 \mathrm{Na}$ entrevista com os tutores, o plágio foi referido em duas situações específicas: uma relacionada à súbita melhoria na qualidade das intervenções de um aluno no fórum, e outra, com a reprodução de parte de um texto na resposta a uma questão discursiva. Na segunda situação, foi feito contato com o aluno mencionando a referência plagiada e solicitada a revisão da resposta. Também foi oferecida a esse aluno a possibilidade de realizar o curso em outro momento, caso seu problema fosse falta de tempo, a fim de garantir a qualidade do curso e a imagem da instituição certificadora. O plágio, segundo um dos tutores, seria devido à percepção de que

o tutor não está presente, não está me vendo, eu consigo burlar essas normas, eu consigo fazer de forma mais superficial (...) Então como é que foi conversado? Na sinceridade, não é? Não teve outro jeito! Foi falado que foi percebido, foi citada a referência, foi encaminhada para ela, mas sempre dando uma oportunidade dela rever a sua situação, (...) nunca fechou a porta, (...) a gente sempre colocou (...) qual é a sua dificuldade? Você não está com tempo? Faz o curso em outro momento. $\mathrm{O}$ que a gente não queria era que o aluno fizesse o curso [apenas] para ser certificado (Tutor 1). 
Além disso, foi percebido também que o fato de as questões discursivas se manterem inalteradas ao longo de várias edições do curso deu margem a que alguns alunos copiassem a resposta de colegas matriculados em turmas anteriores.

\section{A visão dos alunos acerca da aprendizagem on-line}

As expectativas mencionadas pelos alunos entrevistados com relação ao curso foram a aquisição ou atualização de conhecimentos, inclusive competências na área de informação/informática e a capacidade de aplicar os conhecimentos adquiridos no processo de trabalho.

Foi o tema do curso mesmo. Que eu acho que é fundamental para o tipo de trabalho que a gente faz no núcleo: a gestão da tecnologia da informação (Aluno 9).

O tema me interessou porque serve para as ferramentas aqui da central de regulação que são as informações em saúde. Aquela padronização das informações que facilitaria muito a gente e algumas pessoas aqui da central já tinham feito o curso e me recomendaram (Aluno 4).

Também foram referidas expectativas de qualificação e ascensão profissional com benefícios financeiros, sendo que este último só foi obtido por um dos entrevistados. A gratuidade 7 e a modalidade do curso foram citados como elementos motivadores para a sua inscrição.

Quanto à atualização na temática do curso, os alunos referiram que as expectativas foram alcançadas. No entanto, um deles destacou que a forma complexa de apresentação dos conteúdos de uma das unidades de aprendizagem, a despeito de seus conhecimentos prévios, gerou uma expectativa negativa quanto a sua competência para utilizar esses conhecimentos no seu processo de trabalho.

A expectativa inicial era me atualizar. [E ela foi atendida?] No que diz respeito ao que precedeu a questão específica do geoprocessamento, sim. A coisa específica do geoprocessamento, não, [...] porque o que passou ali [...] não acrescentou nada, só colocou minhoca na minha cabeça, que é a questão da necessidade de toda a matemática [...] eu fiquei me perguntando: será que, só se eu tiver todo esse conhecimento estatístico, eu vou ser capaz de fazer uma análise espacial? [...] eu não quero fazer estatística! (Aluno 7).

O acesso ao AVA do curso ocorreu tanto no trabalho quanto no domicílio. $\mathrm{O}$ estudo no domicílio prevaleceu, ocorrendo geralmente à noite e tendo como 
justificativas as demandas, a necessidade de compartilhamento do computador e a existência de conversas paralelas, aspectos que dificultariam o estudo no setor de trabalho. Para alguns entrevistados, o cansaço e as questões familiares comprometiam o acesso no domicílio. De acordo com os relatos dos entrevistados, as dificuldades de acesso relatadas no início do curso, por problemas com login e senha, não comprometeram o seu desempenho. A falta de acesso ao AVA após o término do curso representou, para alguns alunos, a perda do material disponibilizado por tutores e colegas, bem como o pró-prio conteúdo do curso.

Quanto à navegação no AVA, foram citadas como elementos facilitadores a existência de alguma experiência prévia com o uso de computadores e internet.

A principal [habilidade] é você saber utilizar a internet, o computador (Aluno 3).

Olha só, eu acho que ele [o aluno] tem que entender o básico: Windows, Word, principalmente editar alguns textos, e conhecimentos básicos de internet. Tudo básico (Aluno 1).

As ferramentas 'ajuda' e 'fale com o tutor' atenderam aos seus propósitos, esclarecendo as dúvidas mais simples e permitindo uma resposta oportuna do tutor. Os alunos apontaram as seguintes dificuldades e limitações do AVA: problemas na ferramenta chat (saídas involuntárias da sala de bate-papo e dificuldade de retorno imediato) e a falta de opção para salvar e/ou imprimir as atividades realizadas no próprio AVA e de correção ortográfica do texto após a postagem da mensagem no fórum. Outras dificuldades mencionadas foram a ausência da numeração das páginas do conteúdo do curso e de uma ferramenta de busca que permitissem a localização de tópicos ou o retorno a pontos específicos, dentro das unidades.

Eu tive um pouco de dificuldade, logo no início, de me localizar no menu à direita. Que era justamente a de decorar, vamos dizer assim, aonde é que eu ia a tal lugar para poder me achar. Não sei se isso é uma questão minha mesmo ou da questão do ambiente (Aluno 9).

Se você interrompesse em algum momento o módulo que estava acessando, teria que navegar página por página tudo que você já tinha navegado para chegar onde estava. Quer dizer: ele não te mostrava onde você tinha parado da última vez. Eu já fiz um curso, anteriormente, que cada etapa que você ia passando ele já ia marcando para você, ele tinha uma sinalização e quando você tivesse que voltar, você já sabia e ia exatamente naquele ponto (Aluno 26).

Às vezes, por exemplo, na lição cinco, citava alguma coisa da lição 1 sobre domínio, poder, política, aí se você quisesse voltar lá, teria que voltar uma série de 
telas intermináveis. (...) Eu acho que faltava uma ferramenta, tipo que uma memória para você ir para trás e para frente dentro do curso (Aluno 1).

A apresentação visual e a organização dos temas abordados no curso foram bem avaliadas pelos alunos, destacando-se a seleção e qualidade do conteúdo ('relevante', 'claro', 'interessante', 'com encadeamento lógico dos conteúdos') que teria facilitado a aprendizagem. Ainda assim, um dos entrevistados considerou infantil a forma de apresentação das unidades de aprendizagem.

A apresentação é meio infantilzinha. Um bonequinho... aparece uma casinha... umas fotozinhas... assim, meio infantil, mas o conteúdo estava perfeito! Eles trouxeram informações. Eles colocavam frases de filósofos, frases de sociólogos. Muito inteligente (Aluno 4).

Foi mencionado que a distribuição dos conteúdos do curso, em diversas telas, tornou a leitura mais amigável, porém exigia mais tempo para navegação no AVA, principalmente ao se utilizar conexão discada.

Esse meu curso eu achei bastante interessante. As informações não eram muito pesadas na tela, elas vinham aos poucos, tinha exemplos, você acessava os exercícios ao longo das unidades também. Tinham uma maneira soft, né? Eu achei amigável (Aluno 7).

Outra questão, com relação especificamente à organização do conteúdo, é o texto. (...) Eu achava que poderia não ser tão picado, tá entendendo? Na tela. Eu preferiria, eu sei que ficava muito mais amigável aquele texto daquela maneira, mas vá adiante! siga adiante!, aquilo eu achava que levaria menos tempo se tivesse um texto corrido, da própria apresentação do módulo. Eu sei que é para ficar mais amigável, mas aquilo fazia demorar mais tempo. Numa conexão que não é banda larga faz diferença, faz muita diferença! (Aluno 9).

Uma queixa recorrente entre os entrevistados foi a ausência de material impresso, levando-os a adotar, como estratégia de estudo, a sua impressão.

Eu senti falta de um material impresso (...) eu estou fazendo agora o [curso] facilitador [Formação de Facilitadores de Educação Permanente em Saúde], eu tenho um material impresso. Quando eu uso o computador, já estou com aquilo ali pronto, aí sento, é rapidinho. É cansativo você ficar lendo aquele texto, para analisar na hora, eu acho que fica meio complicado. Se a gente tem um material impresso, pode sentar com mais calma. Sei lá, um horariozinho que eu tenho, eu pego aquilo, leio, aí quando eu vou lá para a rede é mais rápido (Aluno 2). 
Ainda que os alunos tenham considerado as atividades compatíveis com o cronograma definido, eles destacaram que os tutores foram flexíveis com respeito aos prazos estabelecidos inicialmente pela coordenação do curso.

Nós tivemos bons prazos. Nada ficou apertado. [...] É aquilo que eu te falei: se você tivesse disciplina, que você precisa ter para fazer um curso de educação a distância, você consegue levar o curso tranquilamente. Porque prazo tem. Não tem porque se atrasar, deixar de entregar as atividades (Aluno 4).

No que diz respeito aos aspectos que facilitaram o desempenho dos alunos, a existência de conhecimentos prévios em saúde pública e sistemas de informação, a autodisciplina, a capacidade de gerenciamento do tempo de estudo e o compromisso, foram os mais citados.

O compromisso em finalizar o curso parece ter sido afetado pela participação concomitante em outro curso e também pelo tipo de modalidade de ensino, colocando em evidência a preferência de alguns alunos pela aprendizagem presencial. As dificuldades relatadas dizem respeito a algumas características relativas à participação em um curso a distância, tais como a necessidade de digitar ao mesmo tempo em que se pensa na resposta, a exposição das ideias por meio da escrita, a qualidade da intervenção em termos de domínio do tema, o uso da linguagem abreviada para comunicação e a interação a distância com a turma.

A disciplina foi um termo utilizado de maneira recorrente pelos alunos ao se referirem à auto-organização como uma competência metacognitiva necessária ao bom desempenho em um curso on-line. Não obstante, apenas um aluno reconheceu que o cronograma disponibilizado seria um recurso que favoreceria a auto-organização do estudo.

O volume de atividades, eu não achei demais não, nem de menos. Agora, o aluno precisa se organizar. $\mathrm{O}$ fato de ter aquele cronograma antes de começar o curso é ótimo. Porque aí você se organiza tanto para fazer o curso quanto para suas outras atribuições: a data que eu tenho para entregar os trabalhos, até quando eu posso participar do fórum. Aquele cronograma do início é essencial para a gente se organizar. Aí você, tendo uma certa organização, consegue cumprir todas as atividades sem problema (Aluno 5).

O contexto de vida e trabalho dos alunos, bem como questões de gênero, também foram mencionados como fatores que exigiam a adoção de diversas estratégias para a gestão do tempo de estudo, contrapondo-se à ideia de que essa dependeria exclusivamente da capacidade de organização do aluno. 
Eu ia ajustando para não ficar defasada em relação ao ritmo do curso, porque tinha as datas para entregar os trabalhos e eu procurei não furar, entende?, as datas, mas aí, cada período eu tinha uma estratégia, que dependia do meu outro trabalho, dependia de fazer uma série de acertos (Aluno 7).

Porque assim, $[\ldots]$ eu acho que a mulher acaba sendo atrapalhada por isso. Porque se a mulher está em casa [...] ninguém a substitui. Quando é o homem, eu vejo isso pelo meu marido, ele está fazendo um curso, aí eu tento organizar as coisas para que não atrapalhe ele [...], mas quando sou eu, ao contrário, é mais difícil, até pela situação da criança que te vê ali, que não vai sossegar... (Aluno 6).

Outro aspecto associado à questão do tempo foi o tipo de abordagem de estudo adotado pelo aluno. Um depoimento sublinha que o aprofundamento nas leituras recomendadas exigiria maior tempo para a consecução das atividades e cumprimento dos prazos.

Essa foi uma questão. Ele [o curso] me exigia mais tempo. Para ler com profundidade, fazendo as análises que eram solicitadas nas questões, utilizando uma compreensão analítica e comparativa dos textos, tinha que sentar mais tempo do que eu esperaria para fazer o curso, o que demandaria uma carga horária grande. (Aluno 9).

A primeira coisa que você tem que fazer é se organizar: para não chegar no meio do caminho e ficar sobrecarregada e acabar desistindo. [...] têm vários textos sugeridos [para leitura] e se você não tiver uma certa disciplina, você pode acompanhar o curso só fazendo o básico e não fazer as leituras, o que te dá um suporte muito maior [fazer as leituras complementares], ajuda na conclusão, você forma suas ideias e tem um entendimento melhor de todo o conteúdo (Aluno 5).

A comunicação com a turma e o apoio constante do tutor, especialmente no início do curso, foram avaliados de maneira positiva pelos entrevistados. A principal característica destacada quanto ao desempenho dos tutores foi a habilidade para motivar e incentivar a participação dos alunos no curso.

A tutora foi muito interessada. Ela animava... vamos lá! (Aluno 7).

Muito bom mesmo [os comentários do tutor]. Muito interessante. Eu vi que a pessoa estava realmente de corpo e alma e dominava o tema. E ela chamava, ela fazia chamamentos à participação no fórum. Para a gente trocar entre a gente (Aluno 9).

Ela sempre falava: Gente, essa participação no fórum precisa ser maior! Vocês precisam entrar mais, colocar mais as suas ideias! Tenho certeza que você tem algo mais a acrescentar. Ela sempre me incentivava a escrever mais (Aluno 4). 
Quando não participávamos do fórum ela chamava. É bastante importante essa presença do tutor para estimular. Ainda mais que é um curso a distância. Tem que ter o comprometimento do aluno, o aluno tem que ter interesse. Senão acaba deixando de lado e pode até chegar a não concluir o curso. Esse papel do tutor de buscar, de trazer e de colocar questões interessantes, que despertam o interesse do aluno (Aluno 5).

Dentre as estratégias de motivação adotadas pelos tutores, segundo os alunos, destacam-se: a elaboração de questões capazes de despertar o interesse; comentários claros, qualificados, relevantes e oportunos; críticas de incentivo à aprendizagem; sugestão de leituras complementares e o atendimento oportuno às demandas dos alunos.

Eu tirei as dúvidas com ela [tutora]. Ela sempre pronta para atender. Eu enviava a dúvida de manhã, à tarde já estava com a resposta (Aluno 4).

Ela era, a tutora, extremamente disponível. Ficava até impressionada, positivamente surpresa (...) (Aluno 9).

Teve uma vez que eu recebi uma crítica nesse sentido: você tem o pensamento correto, (...) mas você poderia escrever um pouco mais. Não responda tão pontual e objetivo, desenvolva melhor! E isso vale como um incentivo. Primeiro para o aluno saber se está no caminho certo, se é isso mesmo que eu estou pensando. Você está ali sozinho, diferente de uma sala de aula. (Aluno 5).

Outras habilidades reconhecidas nos tutores, pelos alunos, foram: a capacidade de avaliar de forma clara e objetiva; o domínio das ferramentas, do ambiente e do conteúdo; apoio frente às dificuldades em permanecer no curso, por exemplo, flexibilizando prazos para o cumprimento das atividades.

Ajudaram bastante [as intervenções da tutora no fórum]. Tanto para as pessoas que não estavam participando do fórum quanto para quem estava participando e colocava alguma pergunta; nunca ficava sem resposta. Ou se algum outro colega trouxesse uma informação, ela estava complementando o tempo todo. Você nunca ficava sem um retorno, uma resposta. Isso é bastante importante (Aluno 5).

Ela fazia intervenções que demonstrava claramente que ela tinha conhecimento (Aluno 26).

Tendo em vista a diversidade dos temas abordados no curso, os entrevistados foram questionados sobre a necessidade de ter ou não mais de 
um tutor e, nesse sentido, eles consideraram que o acompanhamento de um único tutor favoreceria uma melhor avaliação de desempenho e participação dos alunos.

Para mim não houve nenhum problema ter um tutor para todas as unidades, agora, na coisa mais específica, por exemplo, do geoprocessamento, talvez pudesse ter avançado um pouco mais, se tivesse um tutor específico, especializado. Mas também, acho que o objetivo do curso não era esse, era só fazer uma introdução à temática (Aluno 7).

Não seria legal não [ter mais de um tutor], porque ia ficar muito segmentado, muito dividido. Você estaria praticamente, a cada lição, que demorou em torno de quatro semanas, com uma pessoa. Você vindo... uma única pessoa, do início ao fim, teria uma determinada familiaridade, uma cumplicidade, uma parceria. Eu acho essa ideia ruim (Aluno 1).

Provavelmente a falta de experiência em cursos a distância, a participação em cursos com um único tutor e a satisfação com a tutoria contribuíram para que não fossem consideradas, pelos entrevistados, as potencialidades da adoção de tutores distintos, de acordo com a especificidade dos temas.

A percepção do fórum como estratégia pedagógica que propicia uma aprendizagem significativa e contextualizada, ao criar um espaço de comunicação e interação para troca de conhecimentos e experiências diversificados, foi compartilhada apenas por um terço dos entrevistados. Os demais consideraram sua participação no fórum como atividade obrigatória, pro forma e sem importância para o seu processo de aprendizagem. Cabe ressaltar que a baixa participação esteve também referida à dificuldade individual de interação virtual.

Eu usei bastante o fórum. $\mathrm{O}$ fórum era interessante porque o tutor está instigando os alunos a falarem alguma coisa, colocarem. É justamente onde você associa o que você está adquirindo de conhecimento com a sua prática. Porque você coloca ali exemplos, o que que aconteceu, como você lida com determinadas situações (Aluno 5).

[Quanto ao fórum] todos os temas [eram] muito pertinentes. Todas as colocações eram extremamente relevantes, porque cada um tinha uma experiência, cada um trabalhava no setor. Então teve diversidade de colocações, de opiniões, de visões. A troca de informações era muito valiosa. Eu realmente gostei! (Aluno 4).

Não conseguia acessar muito porque não tinha tempo para ficar lá no fórum. No fórum eu não consegui conversar muito. Eu acho que eu não consigo muito essa 
coisa de conversar virtualmente com as pessoas... Então, era uma dificuldade individual minha: de ficar no fórum discutindo, sem estar com as pessoas presentes (Aluno 25).

Ainda que não tenham sido diretamente questionados quanto à distinção entre as modalidades de ensino presencial e a distância, a comparação entre ambas esteve presente na fala de alguns entrevistados, como se percebe na citação abaixo:

Porque a discussão é legal para quando você está numa turma, naquele horário (...) no presencial é legal a discussão. (...) Aquilo [o fórum de discussão] foi me desinteressando. A discussão às vezes caía um pouco de nível e com coisas muito... assim... dava pouco conhecimento pra gente. (...) não me provocava para entrar nelas [discussões] . Eu lia: Ah, legal. Muito de fora! Ou seja, não me senti fazendo parte de uma turma, de estar propondo (Aluno 6).

Um dos alunos destacou que um perfil caracterizado pela familiaridade com a escrita digital associado à ocorrência de um momento presencial favoreceria o bom desempenho num curso a distância e o estabelecimento de relações de confiança entre alunos e tutores.

Olha, eu acho que tem que ter um perfil. Eu acho que nem todo mundo... tem muitas pessoas que têm dificuldade nessa coisa de... Como eu, (...) eu tenho dificuldade em digitar, preciso passar primeiro para o papel, concatenar as ideias direitinho para depois digitar. (...) Essa é a limitação: dominar as ferramentas básicas da informática, da computação (Aluno 1).

Eu sei que a visão do coordenador era totalmente não presencial, mas (...) teve determinadas horas que eu achei que as pessoas davam respostas entre a verdade e a mentira, entre o real e o virtual, alguma coisa tipo 'politicamente correto'. Porque eu não sei quem está do outro lado ou o que pode falar ou fazer comigo. Está entendendo? Eu achei que faltou de muita sinceridade. (...), as pessoas tinham muita cautela, por não saber com quem estão lidando. (...). Eu acho que se tivesse pelo menos um encontro mensal dentro do curso seria muito bom. Porque eu acho que olhando cara a cara, talvez algumas respostas seriam bem diferentes (Aluno 1).

Outro entrevistado referiu que um curso na modalidade a distância combinado com momentos presenciais imputa maior compromisso e responsabilidade no cumprimento das atividades.

Então a gente tem que se reunir e aí todo mundo leva o seu material. Cada um [diz]: Olha, respondi assim porque eu acho isso, eu acho aquilo, aí chega a um consenso 
para fechar a resposta para encaminhar. Então, obrigatoriamente eu (...) não vou chegar lá com o livro vazio. (...) tem que apresentar alguma coisa (Aluno 2).

A comparação entre as duas modalidades de ensino está referida a toda uma experiência prévia de aprendizagem dos alunos com a modalidade presencial.

Eu me interessei pela metodologia ser a distância. Porque me facilitaria, não teria que me deslocar até lá. Depois eu vi que não era uma boa estratégia. (...) O fato de ser a distância é um facilitador e um dificultador. (...) Olha, então não tenho essa disciplina de fazer isso, não sou madura o suficiente para estar, mesmo com vontade, deixando aquele tempo para aquilo. Eu comecei a avaliar isso para mim e falei: Bom, o curso a distância para mim não serve, não dá. Eu não vou conseguir porque eu não tenho essa disciplina. Então eu preciso de curso presencial. (...) Até porque é um estímulo, eu estava acostumada a cursos presenciais. (...) desde sempre a nossa atividade foi presencial. Alguém cobrando, aquela coisa de você ter que ir estudar. No início do curso, quando eu me inscrevi, (...) tenho interesse no assunto, tenho disposição de tempo para fazer isso à noite. Porque, no campo do mental, você acha que está apto a fazer aquilo ali. Quando vai para a prática, é que você vê, é bem diferente (Aluno 6).

\section{Discussão}

A partir dos relatos dos entrevistados surgem questões que, embora não estejam limitadas à modalidade de educação a distância, se tornam mais destacadas em decorrência da sua relevância na aprendizagem on-line. A educação a distância está apoiada fundamentalmente na comunicação escrita, o que requer capacidade de síntese para a exposição de ideias em seus aspectos principais; domínio da língua portuguesa (ortografia, gramática, sintaxe) e a posse de um código social que facilite a expressão de ideias na ausência dos sinais não-verbais, presentes na comunicação oral ('netiqueta'). O conjunto dessas características remete ao conceito de letramento, definido como estado ou condição de quem exerce as práticas sociais de leitura e escrita e participa de eventos onde a escrita é parte integrante tanto da interação entre pessoas quanto do processo de interpretação dessa interação (eventos de letramento) (Soares, 2002). Como destaca essa autora, nessa interação são requeridas habilidades e atitudes que possibilitam a participação ativa e levam à formação de competências discursivas e cognitivas que conferem aos participantes um determinado estado ou condição diferenciada de inserção numa sociedade letrada. Na educação a distância, às habilidades computacionais requeridas para o uso das tecnologias de informação e 
comunicação soma-se a posse por tutores e alunos de letramento digital, um estado ou condição que adquirem os que se apropriam da tecnologia digital e exercem práticas de leitura e de escrita por meio do computador. Enquanto o uso disseminado do computador e da internet poderia explicar a baixa frequência de menções acerca das dificuldades no uso do ambiente, as habilidades decorrentes do letramento digital mostraram-se como um elemento importante tanto na participação dos alunos nos fóruns quanto nas estratégias adotadas pelos tutores na interação com os alunos.

Carvalho e Misoczky (2001) associam a dificuldade na escrita on-line às características de uma forma de comunicação que requer o uso de recursos sintáticos e semânticos, cujo objetivo é mimetizar os significados de manifestações inerentes à comunicação presencial. Esses autores assinalam também que os fóruns de discussão colocariam em xeque o paradigma da educação domesticadora e as relações de poder dentro do grupo, tendo em vista o seu aspecto aberto e democrático, onde todos podem expressar sua compreensão particular das questões discutidas. A autonomia concedida ao aluno lhe dá um papel mais ativo na construção de um conhecimento compartilhado, mas exige uma argumentação mais articulada e maior consistência ao seu discurso.

A participação em espaços virtuais coletivos significa assumir a responsabilidade na construção do próprio conhecimento, não obstante isso o obrigue a expressar publicamente suas opiniões que, uma vez registradas, estarão permanentemente sujeitas ao julgamento e à contestação do grupo. Nesse estudo, o que se verificou foi que se, de um lado, o fórum foi considerado pelos tutores como um importante espaço de articulação de conhecimento e de interação social, uma parcela importante dos alunos não compartilhou dessa perspectiva. Os resultados dessa pesquisa apontam para o fato de que há uma ênfase no uso de estratégias de interação no curso, em concordância com a literatura especializada, mas a adoção dessas estratégias deve ser ponderada pelos aspectos socioculturais e históricos do contexto em que se insere o curso (Shin, 2002).

Experiências prévias de interação dos alunos, em salas de aula virtuais, no uso de tecnologias de informação e comunicação, síncrona e assíncrona, como mensagens, chat, redes sociais, modelam o alcance das estratégias de interação on-line (Silva, 2003). Por esta razão, se o uso do correio eletrônico pode reforçar o caráter transmissionista da pedagogia bancária, limitar a continuidade e a coerência das conversas e, consequentemente, reduzir a interação e o sentimento de pertencimento a um grupo ou comunidade, essa ferramenta também se apresenta como estratégia de comunicação que propicia uma situação mais confortável e segura ao aluno. O conforto e segurança adviriam da familiaridade no uso dessa ferramenta e a possibilidade de uma comunicação mais reservada com o tutor e os colegas. 
Outro aspecto que influencia a interação dos alunos num curso a distância é a disponibilidade do tutor que, segundo os informantes desse estudo, estaria relacionada à capacidade desse profissional de estimulá-los a participar mais em espaços coletivos, como o fórum. A 'presença social', grau em que o indivíduo sente ou é visto como real pelos colegas trabalhando em um ambiente virtual, tem sido utilizada para explicar o sentimento de contato numa situação de comunicação mediada pelas tecnologias de informação e comunicação (Hill et al., 2003), tais como a percepção dos alunos quanto à proximidade com o tutor. Os resultados dessa pesquisa apontam que o tutor exerceu um papel fundamental para estimular esse sentimento de presença social nos alunos. Belloni (2003) destaca que o maior desafio a ser enfrentado por instituições que adotam a educação a distância refere-se mais a questões de ordem socioafetiva (estratégias de contato e interação) do que necessariamente a conteúdos e métodos. Nesse aspecto, destaca-se o sistema de tutoria, mais especificamente, a atuação do tutor, que na interação com os alunos vem exercendo um papel fundamental no que se refere à conexão desses aspectos.

O papel desempenhado pelo tutor na participação do aluno evidencia o desafio das propostas de aprendizagem construtivistas que seria deslocar-se do papel de dispensador de informação em direção à atuação como guia para descoberta. No entanto, o tutor se vê diante de dificuldades em adequar seus conhecimentos e experiências, no que se refere à aprendizagem, às estratégias pedagógicas do curso e ao modo como alunos manejam suas próprias experiências nessa modalidade de ensino. Torna-se mais difícil criar um ambiente de aprendizagem colaborativo quando a única experiência são as aulas presenciais (Tallent-Runnels et al., 2006). Embora os tutores estejam cientes de que seu papel é prover os alunos com ajuda e orientações claras e suficientes, mantendo-os na sua zona de desenvolvimento proximal (Vygotski, 2007), deparam-se, frequentemente, com o desafio frente ao volume de informações e como elas devem ser oferecidas ao aluno. Nesse sentido, os tutores precisam decidir acerca da melhor oportunidade de intervenção sem antever qual será a percepção do aluno, que pode, de um lado, entender como um desafio a construção do conhecimento ou, de outro, como desinteresse/descaso do tutor. A ausência no ambiente on-line do contato presencial e de indicações não-verbais que sinalizam quanto à adequação das estratégias pedagógicas adotadas requerem a disponibilidade de instrumentos e procedimentos que permitam uma detecção precoce dos problemas no processo de aprendizagem e, consequentemente, uma ação efetiva do tutor para minimizar possíveis 'ruídos' na comunicação com os alunos.

As reuniões periódicas entre tutores e a coordenação geral do curso constituíram um espaço de troca de conhecimentos e discussões sobre os conteúdos abordados e estratégias pedagógicas utilizadas (melhores práticas 
de tutoria). Esses encontros fomentaram a construção de uma estratégia de orientação pedagógica que auxiliou os tutores a manejarem diferentes situações, tais como a negociação de prazos, consenso quanto aos elementos comuns para a avaliação dos alunos, meios para contornar conflitos e estratégias para lidar com o plágio. As razões apontadas para o plágio são o desejo de uma nota melhor, preguiça ou mau gerenciamento do tempo, falta de compreensão das regras de um curso a distância, menor compromisso com o processo de aprendizado, maior interesse no certificado e a percepção da internet como uma biblioteca universal na qual todo o material é gratuito. Além disso, a sensação de invisibilidade derivada da distância física e do 'anonimato' das relações dos participantes, ou seja, a circunstância de não ser conhecido pelo tutor poderia constituir um fator adicional para a ocorrência do plágio. O plágio gera uma situação desconfortável ao ser percebido pelo tutor como uma 'quebra' do contrato de confiança e por sinalizar, para o tutor e o aluno, a existência de problemas no processo ensino-aprendizagem on-line. Hart e Friesner (2004) sugerem como o passo mais importante para diminuir o plágio a mudança no material de avaliação entre as diferentes edições do curso que exija um grau de autorreflexão por parte do estudante e teste suas habilidades para o pensamento crítico, de modo que eles entendam a avaliação como um processo de colaboração e não um 'arranjo' com vistas à redução do volume de trabalho e esforço. Outras medidas podem ser adotadas para reduzir o plágio, tais como a solicitação de anexar fotocópias de algumas referências citadas no trabalho, ensino e reforço das convenções acadêmicas (por exemplo, citação), orientação no gerenciamento do tempo e indicação aos alunos que um trabalho descritivo terá notas mais baixas que respostas com uma avaliação mais crítica.

Uma estratégia adotada pelos tutores entrevistados para identificar possíveis situações de plágio é a detecção de mudanças abruptas na qualidade das intervenções e/ou atividades dos alunos e uso de excertos do texto do aluno para rastreamento em sítios de busca na internet. Entretanto, a ausência nos processos de formação de tutores de discussões e orientações acerca dos procedimentos a serem adotados em face da suspeita ou comprovação de plágio deixa a cargo do tutor a escolha de qual seria a melhor forma de lidar com essa situação e o ônus das consequências das decisões tomadas.

Quanto às estratégias cognitivas e metacognitivas adotadas pelos alunos, o autogerenciamento do tempo e o aprofundamento ou não nas atividades de aprendizagem foram citados como razões para explicar o seu grau de participação no curso. A disciplina, associada ao autogerenciamento do tempo, foi uma habilidade de estudo mencionada pelos tutores e alunos como condição necessária para aprendizagem centrada no aluno em um curso on-line. Não obstante esse reconhecimento, verifica-se que dificuldades enfrentadas pelos alunos no decorrer do curso tiveram relação exatamente com esse aspecto. 
Segundo Beloni (2003), no EAD a centralidade está no aprendiz, o aluno é concebido como um ser autônomo e capaz de realizar a gestão do seu processo de aprendizagem. Contudo, o que estudos realizados em diversas experiências apontam é uma imagem bem distinta desse ideal. A flexibilidade aparente de realização de um curso a distância não é percebida pelo aluno no que se refere ao tempo, tendo em vista a exigência no cumprimento de prazos e a linearidade na realização do curso. Ademais, deve-se considerar ainda o contexto de vida dos alunos, que, no âmbito dessa pesquisa, se caracterizou pela falta de condições de realização dos estudos no período de trabalho, exigindo que os alunos se organizassem para estudar em horário noturno e/ou nos finais de semana. A independência do aluno em realizar seus estudos no momento mais adequado, no decorrer do curso, pode ser sentida como um peso, justamente pela falta da autonomia necessária na gestão do estudo. Nesse sentido, a sensação de não conseguir corresponder ao esperado em termos das habilidades/atitudes necessárias a um aluno de um curso a distância pode contribuir negativamente para sua automotivação, ao mesmo tempo em que engendra um sentimento de culpa/fracasso frente ao insucesso.

Outra questão importante a ser considerada refere-se à oferta ou não de material didático aos alunos, seja na sua forma impressa ou mídia eletrônica (CD-ROM). Por um lado, a disponibilização desse material aos alunos de um curso a distância favorece a superação de desigualdades territoriais no tocante ao acesso e à qualidade da tecnologia disponível. Entretanto, essa opção pode inibir o acesso e o uso do AVA, prejudicando o processo de interação e colaboração on-line. Além disso, esse material distribuído poderia estar sujeito à necessidade de reimpressão para correção de erros e à desatualização frente ao conteúdo disponível on-line, que, teoricamente, ofereceria maiores facilidades para sua atualização e correção. No entanto, o que se pôde observar é que essa atualização não ocorre de forma tão dinâmica e rápida como fora suposto no momento da concepção do curso. A ideia de combinar a oferta de material didático com incentivos de acesso ao AVA, por meio de dispositivos de avaliação/participação/discussão coletiva, como chat e fórum, pode servir de alternativa para superação dessas questões, como já vem sendo realizado em outras experiências.

\section{Conclusão}

A partir das análises feitas neste estudo chega-se a algumas conclusões acerca do uso de ambientes virtuais para a aprendizagem profissional on-line. O que se pode apreender da entrevista com os alunos e tutores é a necessidade de readequação periódica da proposta pedagógica do curso on-line, de modo a 
atender as demandas dos alunos e tutores quanto à organização e atualização dos conteúdos, os meios de acesso ao material e a implementação de atividades avaliativas compatíveis com a experiência de trabalho. A análise das escolhas feitas ao formular um curso e as implicações na sua condução e gerenciamento devem ser revistas com o objetivo de compatibilizá-lo às experiências vivenciadas ao longo de suas diversas edições. A concepção de um curso com conteúdos elaborados por diferentes autores requer a articulação entre um plano de trabalho e os processos de ensino-aprendizagem. A falta de integração entre as unidades de aprendizagem e a presença de distintos níveis de aprofundamento desses conteúdos pode levar o tutor a articular e ajustar esses níveis, exigindo conhecimentos prévios e habilidades que, muitas vezes, não são contempladas nos processos formativos desses profissionais. Do mesmo modo, a forma de apresentação adotada nos ambientes virtuais de aprendizagem deve buscar um equilíbrio entre a densidade e a abrangência dos conteúdos necessários e o uso de recursos midiáticos, como vídeos ou animações, bem como a disponibilidade em diferentes formatos (impressos, CD-ROM) pode facilitar a aprendizagem de alunos com baixa escolaridade e pouca familiaridade com a leitura e a escrita, além de contornar as limitações tecnológicas relativas ao acesso à internet.

Essas mudanças implicam uma avaliação contínua e integrada à gestão educacional que seja capaz de apontar os limites das estratégias pedagógicas e recursos midiáticos utilizados em distintos grupos de alunos, com vistas a subsidiar a sua reformulação e adequação às novas demandas que surgem nos processos de trabalho em saúde.

\section{Nota do Editor}

A pesquisa que deu origem a este artigo foi financiada com recursos provenientes da terceira edição do Projeto de Indução à Pesquisa e Desenvolvimento Tecnológico, do Instituto de Comunicação e Informação Científica e Tecnológica em Saúde, Fundação Oswaldo Cruz (Icict/Fiocruz), e aprovada pelo Comitê de Ética da Fundação Oswaldo Cruz (n. ${ }^{\circ}$ 0028.0.011.000-07). 


\section{Notas}

1 Pesquisador do Laboratório de Informação em Saúde do Instituto de Informação e Comunicação Científica e Tecnológica em Saúde da Fundação Oswaldo Cruz (LIS/Icict/ Fiocruz). Rio de Janeiro, Brasil. Doutor em Saúde Pública pela Escola Nacional de Saúde Pública Sergio Arouca (Ensp/Fiocruz).<jlaguardia@cict.fiocruz.br>

Correspondência: Avenida Brasil, 4.365, Pavilhão Haity Moussatché, Manguinhos, Rio de Janeiro, Brasil, CEP 21040-900.

2 Pesquisadora-professora do Laboratório de Educação Profissional em Vigilância em Saúde da Escola Politécnica de Saúde Joaquim Venâncio da Fundação Oswaldo Cruz (Lavsa/ EPSJV/Fiocruz), Rio de Janeiro, Brasil. Mestre em Saúde Coletiva pelo Instituto de Medicina Social da Universidade do Estado do Rio de Janeiro (IMS/Uerj). < angelacasanova@fiocruz.br>

3 Tecnologista do Laboratório de Ciência, Tecnologia e Inovação em Saúde do Instituto de Informação e Comunicação Científica e Tecnológica em Saúde da Fundação Oswaldo Cruz (LabCities/ICcict/Fiocruz). Mestre em Saúde Pública pela Escola Nacional de Saúde Pública Sergio Arouca (Ensp/Fiocruz). <rejane@cict.fiocruz.br >

4 Inicialmente estava prevista a participação obrigatória dos alunos nos chats, esta participação serviria inclusive para compor o conjunto de estratégias de avaliação do curso.

5 Atualmente o AVA foi ajustado de maneira a possibilitar o uso da ferramenta "Chat".

6 O plágio tem sido referido na literatura como um problema comum na EAD, especialmente quando não há nenhuma etapa do processo avaliativo realizado em momento presencial.

7 O curso foi custeado pela Secretaria de Estado de Saúde e Defesa Civil do Rio de Janeiro para ser oferecido aos seus trabalhadores, bem como aos profissionais das secretarias municipais de saúde.

\section{Referências}

BELLONI, Maria Luiza. Educação a distância. Campinas: Autores Associados, 2003.

BROSNAN Kevin; BURGESS Robin C. Web based continuing professional development: a learning architecture approach. The Journal of Workplace Learning, v. 15, n. 1, p. 2433, 2003.

CARVALHO, Nilson M.; MISOCZKY, Maria Ceci. A. Potencialidades da aprendizagem virtual: uma reflexão a partir da experiência do curso de planejamento estratégico em saúde. In: MISOCZKY, Maria Ceci et al. (Org.) Educação a distância: reflexões críticas e experiências em saúde. Porto Alegre: Dacasa Editora/Programa de Desenvolvimento da Gestão em Saúde - PDG Saúde, 2001. p. 65-83.

CLEGG, Sue; HUDSON, Alison; STEEL, John. The emperor's new clothes: globalization and e-learning in Higher Education. British Journal of Sociology of Education, v. 24, n. 1, p. 39-53, 2003. 
GIBSON, David. Network-based assessment in education. Contemporary Issues in Technology and Teacher Education, v. 3, n. 3, p. 310-23, 2003.

HART, Mike; FRIESNER, Tim. Plagiarism and poor academic practice: a threat to the extension of e-Learning in Higher Education? Electronic Journal on e-Learning, v. 2, n. 1, p. 89-96, 2004.

HILL, Janette R. et al. Exploring research on internet-based learning: from infrastructure to interactions. In: JONASSEN D. H. (ed.) Handbook of research on educational communications and technology, New York: Macmillan, 2003. p. 433-60.

LAGUARDIA, Josué.; PORTELA, Margareth. C.; VASCONCELLOS, Miguel. M. Avaliação em ambientes virtuais de aprendizagem. Educação \& Pesquisa, São Paulo, v. 33, n. 3, p. 513-30, 2007.

MOORE, Michel; KEARSLEY, Greg. Educação a distância: uma visão integrada. São Paulo: Cengage Learning, 2008.

OSBORNE, Michael.; OBERSKI, Iddo. University continuing education. The role of communications and information technology. Journal of European Industrial Training, v. 28, n. 5, p. 414-428, 2004.

SHIN, Namin. Beyond interaction: the relational construct of 'Transactional Presence'. Open Learning, v. 17, n. 2, p. 21-37, 2002.
SILVA, Marco (Org.). Educação on-line. São Paulo: Edições Loyola, 2003.

SOARES, Magda. Novas práticas de leitura e escrita: letramento na cibercultura. Educação e Sociedade, Campinas, v. 23, n. 81, p. 143-160, 2002.

TALLENT-RUNNELS, Mary K. et al. Teaching courses online: a review of the research. Review of Educational Research, v. 76, n. 1, p. 93-135, 2006.

TORREZ, Milta N. F. B. Educação a distância e a formação em saúde: nem tanto, nem tão pouco. Trabalho, Educação e Saúde, Rio de Janeiro, v. 3, n. 1, p. 171-86, 2005.

VALCKE, Martin M.; LEEUW, Frans L. Evaluating digital distance learning programs and activities. Washington: World Bank Institute, 2000. 75 p.

VYGOTSKI, Lev S. A formação social da mente. São Paulo: Martins Fontes, 2007.

WENTLING, Tim L. et al. E learning: a review of literature. Knowledge and Learning Systems Group, University of Illinois at Urbana-Champaign, 2000. Disponível em: $<$ http://learning.ncsa.uiuc.edu/papers/ elearnlit.pdf $>$ Acesso em: 5 mar. 2005.

Recebido em 25/02/2010

Aprovado em 18/03/2010 